\title{
ZAP-70 and CD38 expression are independent prognostic factors in patients with B-cell chronic lymphocytic leukaemia and combined analysis improves their predictive value
}

\author{
Iwona Hus ${ }^{1}$, Agnieszka Bojarska-Junak ${ }^{2}$, Anna Dmoszyńska ${ }^{1}$, Ewa Wąsik-Szczepanek ${ }^{1}$, \\ Małgorzata Sieklucka $^{1}$, Wioletta Trześniewska ${ }^{1}$, Magdalena Glazer ${ }^{2}$, Jacek Roliński ${ }^{2}$
}

${ }^{1}$ Department of Haematology and Bone Marrow Transplantation, Medical University of Lublin

${ }^{2}$ Department of Clinical Immunology, Medical University of Lublin

\begin{abstract}
Recently identified biological risk factors in B-cell chronic lymphocytic leukemia (B-CLL) include ZAP-70 and CD38 expression. The present study was conducted to clarify whether a combined analysis could improve predictive impact of these two parameters. We examined the expression of ZAP-70 and CD38 by flow cytometry method in 217 newly diagnosed, consecutive, unselected and well characterized B-CLL patients in relation to laboratory parameters and clinical outcome. We confirmed that both ZAP-70 as well as CD38 were independent of prognostic factors. There was a significant correlation between the percentage of leukemic cells positive for ZAP-70 and the percentage of CD38+CD19+ cells $(\mathrm{R}=0.629$; $\mathrm{p}=0.000001)$. Combined analysis of ZAP-70 and CD38 showed concordant results in 158/217 patients (72.8\%), while in 59 patients the results were discordant $(27.2 \%)$. A mean treatment free survival (TFS) was the longest in ZAP-70-CD38patients (45.6 months, comparing to 13.6 months in ZAP-70+CD38+ group). Also a mean overall survival was the longest in ZAP-70-CD38- patients (224.7 months compared to 77.9 months in ZAP-70+CD38+ patients).
\end{abstract}

Key words: B-cell chronic lymphocytic leukaemia - Prognostic factors - ZAP-70 - CD38

\section{Introduction}

Over the last few years, technological advances have led to identify important biological and genetic parameters related to the clinical course of B-cell chronic lymphocytic leukaemia (B-CLL). The immunoglobulin variable heavy chain $\left(\operatorname{IgV}_{\mathrm{H}}\right)$ gene was determined as one of the most powerful prognostic factors, where B-CLL cases with unmutated $\mathrm{IgV}_{\mathrm{H}}$ genes are characterized by an unfavorable clinical outcome, whereas the prognosis for patients with germline status is unfavourable $[1,2]$. Recently two other prognostic parameters were also identified in patients with B-CLL: intracellular ZAP-70 expression $[3,4]$ and cell-surface expression of CD38 on leukemic cells $[1,5]$. In contrast to technically

Correspondence: I. Hus, Haematooncology Department, Medical University of Lublin, Staszica Str. 11, 20-081 Lublin, Poland; tel.: (+4881) 5345468, fax.: (+4881) 5345605, e-mail: iwohus@wp.pl demanding and expensive method of $\operatorname{IgV}_{\mathrm{H}}$ mutations analysis, both markers can be conveniently measured using the flow cytometry method. ZAP-70 (zetaassociated protein) was shown to be the most promising surrogate marker for $\operatorname{IgV}_{\mathrm{H}}$ mutation status with a high predictive value. CD38 expression was also initially reported by Damle et al. to be correlated with $\mathrm{IgV}_{\mathrm{H}}$ mutations [1], however subsequent studies showed only some degree of correlation [6,7]. Irrespective of the extent of concordance with rearrangement of the $\operatorname{IgV}_{\mathrm{H}}$ genes, CD38 expression was proved by many investigators to be a reliable predictor of the outcome in B-CLL $[8,9]$. In the literature, there are only few studies $[10,11]$, including our preliminary data [12] reporting clinical significance of combined expression of ZAP-70 and CD38 in predicting the outcome of B-CLL patients. In order to clarify further prognostic impact of combined analysis of ZAP-70 and CD38 we examined the expression of both factors in peripheral blood samples obtained from 217 newly diagnosed, consecutive, unselected 
Table 1. Cox regression analysis of prognostic factors for B-CLL.

\begin{tabular}{|c|c|c|c|}
\hline Independent predictors & Hazard ratio & P value & $95 \%$ confidence interval \\
\hline Hb level & 0.766512 & 0.035383 & $(0.598331 ; 0.981967)$ \\
\hline ZAP-70 expression & 1.033586 & 0.032345 & $(1.002785 ; 1.065334)$ \\
\hline CD38 expression & 1.036427 & 0.002653 & $(1.012523 ; 1.060894)$ \\
\hline
\end{tabular}

Table 2. Comparison of laboratory parameters in groups of patients with B-CLL according to ZAP-70 and CD38 expression. $\mathrm{p}^{1}$-between ZAP-70-CD38- group and ZAP-70-CD38+group (not significant); $\mathrm{p}^{2}$-between ZAP-70-CD38- group and ZAP-70+CD38-group; ${ }^{3}$ between ZAP-70-CD38-group ZAP-70+CD38+ group (only significant $\mathrm{p}$ values shown).

\begin{tabular}{|c|c|c|c|c|c|}
\hline Parameter & $\begin{array}{c}\text { ZAP-70-CD38- } \\
(\mathrm{n}=105)\end{array}$ & $\begin{array}{c}\text { ZAP-70-CD38+ } \\
(\mathrm{n}=25)\end{array}$ & $\begin{array}{c}\text { ZAP-70+CD38- } \\
(\mathrm{n}=34)\end{array}$ & $\begin{array}{c}\text { ZAP-70+CD38+ } \\
(\mathrm{n}=53)\end{array}$ & $\begin{array}{c}\mathrm{p} \text { (U Mann- } \\
\text { Whitney test) }\end{array}$ \\
\hline WBC (G/L) & $58.23 \pm 63.66$ & $76.68 \pm 85.02$ & $66.97 \pm 59.91$ & $93.24 \pm 90.92$ & $\mathrm{p}^{3}=0.02$ \\
\hline LYMPH (G/L) & $49.62 \pm 59.85$ & $59.16 \pm 66.64$ & $58.12 \pm 57.22$ & $77.26 \pm 70.68$ & $\mathrm{p}^{3}=0.009 ;$ \\
\hline $\mathrm{Hb}(\mathrm{g} / \mathrm{dL})$ & $13.35 \pm 1.96$ & $12.16 \pm 2.86$ & $12.53 \pm 2.40$ & $12.41 \pm 2.43$ & $\mathrm{p}^{3}=0.01$ \\
\hline PLT (G/L) & $199.5 \pm 74.14$ & $173.00 \pm 67.03$ & $164.59 \pm 69.86$ & $150.46 \pm 71.76$ & $\begin{array}{c}\mathrm{p}^{2}=0.03 \\
\mathrm{p}^{3}=0.0002\end{array}$ \\
\hline B $_{2} \mathrm{M}(\mathrm{mg} / \mathrm{L})$ & $3.03 \pm 1.68$ & $4.93 \pm 4.59$ & $4.07 \pm .25$ & $5.17 \pm 4.04$ & $\mathrm{p}^{3}=0.00008$ \\
\hline LDH (U/L) & $288.24 \pm 129.61$ & $389.29 \pm 248.99$ & $322.13 \pm 126.19$ & $373.02 \pm 192.45$ & $\mathrm{p}^{3}=0.005$ \\
\hline
\end{tabular}

and well characterized B-CLL patients in relation to laboratory parameters and clinical outcome.

\section{Materials and methods}

Patients. Two hundred seventeen newly diagnosed and previously untreated, consecutive, unselected B-CLL patients were enrolled into this study from 1987 to 2006 . Diagnosis of B-CLL was made on the basis of a clinical examination as well as morphological and immunological criteria described by NCI-WG (National Cancer Institute-Working Group) [13]. There were 78 women and 139 men $(\mathrm{M}: \mathrm{F}$ ratio $-1: 1.78$ with a median age of 64 years (range 34 - 86) at the time of diagnosis. Patients were staged according to the Rai classification. Fifty patients were diagnosed at stage 0 and fifty five at stage 1 , sixty at stage 2 , and twenty-five and twenty seven at stages 3 and 4, respectively. For statistical analyses modified Rai stages were used. Fifty patients had low-modified Rai stage, 115 had intermediate stage and 52 had high stage. All peripheral blood samples were collected in heparinized tubes and immediately processed. Mononuclear cells were isolated by density gradient centrifugation on Gradisol L (Aqua Medica, Poland). Interphase cells were removed and washed twice in phosphate-buffered saline (PBS) and then resuspended at $1 \times 10^{6}$ cells for future staining.

Cell-surface antigen expression. Peripheral blood mononuclear cells were stained with the following antibody conjugates: negative control IgG1 FITC/IgG ${ }_{2 a} \mathrm{PE} / \mathrm{IgG}_{2 a} \mathrm{TC}$, anti-CD45 FITC/ antiCD14 PE (Caltag Laboratories, USA), anti-CD19 PE, anti-CD19 FITC, anti-CD3 PE (BD PharMingen, USA), anti-CD19 TC (PECy5), anti-CD5 TC (PE-Cy5), anti-CD3 FITC/ anti-CD19 PE, anti-CD8 FITC/ anti-CD4 PE, anti-CD5FITC/anti-CD19PE (Caltag Laboratories, USA. $5 \mu \mathrm{l}$ of each MoAb was added to the appropriate tubes and incubated for $20 \mathrm{~min}$ at RT. Finally, the cells were washed and analyzed by flow cytometry.

Flow cytometry analysis. Samples were analysed by flow cytometry using a Becton Dickinson FACSCalibur instrument equipped with a 488-nm argon laser. Five data parameters were assessed: linear forward and side scatter (FSC, SSC), FL-1(FITC), FL-2(PE) and FL-3 (CyChrome). An acquisition gate was established on the basis of FSC and SSC that included mononuclear cells and excluded dead cells and debris. For each analysis 10.000 events were acquired and analysed using CellQuest software. Each sample was run with an appropriate isotype control and this was used to define the negatively stained cells.

ZAP-70 staining using Zenon ${ }^{\text {TM }}$ Alexa Fluor 488 Mouse IgG2a Labeling Kit. All samples were stained for ZAP-70 protein expression. We used the method described earlier [14]. Anti-ZAP70 antibody, clone $2 \mathrm{~F} 3.2$ (mouse monoclonal $\mathrm{IgG}_{2 \mathrm{a}}$ ), was purchased from Biomol Research Laboratories. Zenon ${ }^{\mathrm{TM}}$ Alexa Fluor 488 Mouse $\operatorname{IgG}_{2 \mathrm{a}}$ Labeling Kit was obtained from Molecular Probes. CyChrome conjugated monoclonal antibody (MoAb) anti$\mathrm{CD} 5$, CyChrome conjugated MoAb anti-CD19 and PE conjugated $\mathrm{MoAb}$ anti-CD19 were obtained from Caltag Laboratories.

$100 \mu$ of peripheral blood mononuclear cells $\left(1 \times 10^{6} \mathrm{cell} / \mathrm{s} / \mathrm{mL}\right)$ were stained with MoAbs against the cell-surface markers CD19 $\mathrm{PE}$ and CD5 CyChrome. The cells were then fixed in a $1 \%$ paraformaldehyde solution in PBS for 15 minutes at room temperature (RT) and permeabilized with $70 \%$ ethanol for at least 1 hour at $-20^{\circ} \mathrm{C}$. Thereafter, anti-ZAP-70 antibody labelled by the Zenon mouse IgG labelling reagents was added to the sample tubes. The samples were incubated for 30 minutes at RT, washed and immediately analysed by flow cytometry.

Zenon Complex Formation. For ZAP-70 staining $1 \mu \mathrm{g}$ cells of anti-ZAP-70 antibody per $10^{6}$ cells was evaluated. Anti-ZAP-70 antibody was prepared in $20 \mu \mathrm{l}$ of PBS. Next, the Zenon mouse IgG labelling reagent, which contained a fluorophore-labelled Fab fragment, was added to the antibody solution $(5 \mu \mathrm{l}$ of the Zenon labelling reagents were used for each $1 \mu \mathrm{g}$ of $\operatorname{IgG}$ ). The mixture was incubated for 5 minutes at RT. Then $5 \mu$ of the Zenon blocking reagent was added to the reaction mixture. The solution was incubated for additional 5 minutes and applied to the sample. 
Statistical analysis. The statistical significance of the flow cytometric results was analysed by means of the Mann-Whitney U test. Spearman rank test was used to assess the correlation between the variables. Analysis of the effect of potential prognostic factors was undertaken using a Cox regression. Treatment free survival time and overall survival time measured from diagnosis were estimated according to the method of Kaplan-Meier and compared between groups by means of log-rank test. Differences were considered as statistically significant when the p-value was $<0.05$. We used Statistica 5.0 PL software for all statistical procedures.

\section{Results}

\section{Cox proportional hazards regression analysis}

Using Cox proportional hazards regression analysis, we compared ZAP-70 and CD38 expression with other prognostic factors, namely age $>60$ years, clinical stage, white blood cell, lymphocyte and platelet count, hemoglobin level, serum concentration of LDH and $\beta_{2}$-microglobulin $\left(\beta_{2} \mathrm{M}\right)$. Univariate analysis of the overall survival identified 6 significant factors: Rai stage of the disease, platelet count, hemoglobin level and LDH concentration, as well as ZAP70 and CD38 expression, which subsequently were included in multivariate Cox regression analysis. Only hemoglobin concentration, ZAP-70 and CD38 expression remained significant and were confirmed to be independent prognostic factors (Table 1).

\section{Correlation between ZAP-70 and CD38 expression}

Spearman rank-correlation test revealed significant correlation between the percentage of leukemic cells with ZAP-70 expression and the percentage of CD38+CD19+ cells in the whole patients group $(r=0.629 ; p=0.000001)$ (Fig. 1).

To evaluate further correlation between ZAP-70 and $\mathrm{CD} 38$ expression the patients were divided into four groups. Entire correlation between the expression of studied parameters was noted in 158/217 patients $(72.8 \%)$. Among them there were $105 \mathrm{ZAP}$ 70-/CD38- patients (48.4\%) and 53 ZAP-70+CD38+ patients $(24.4 \%)$. Among the remaining 59 patients, 25 were ZAP-70-CD38+ (11.5\%) and 34 ZAP70+CD38- (15.7\%). Table 2 presents the comparison of clinical and laboratory parameters with four groups of patients mentioned above. The most significant differences were revealed among the patients characterized by positive ZAP-70 and CD38 expression as well as lack of expression in the two studied proteins. The differences referred to all evaluated laboratory parameters. The only significant difference among the remaining groups concerned a higher number of PLT count in the group of ZAP-70CD38- patients in comparison with ZAP-70+CD38ones (Table 2).

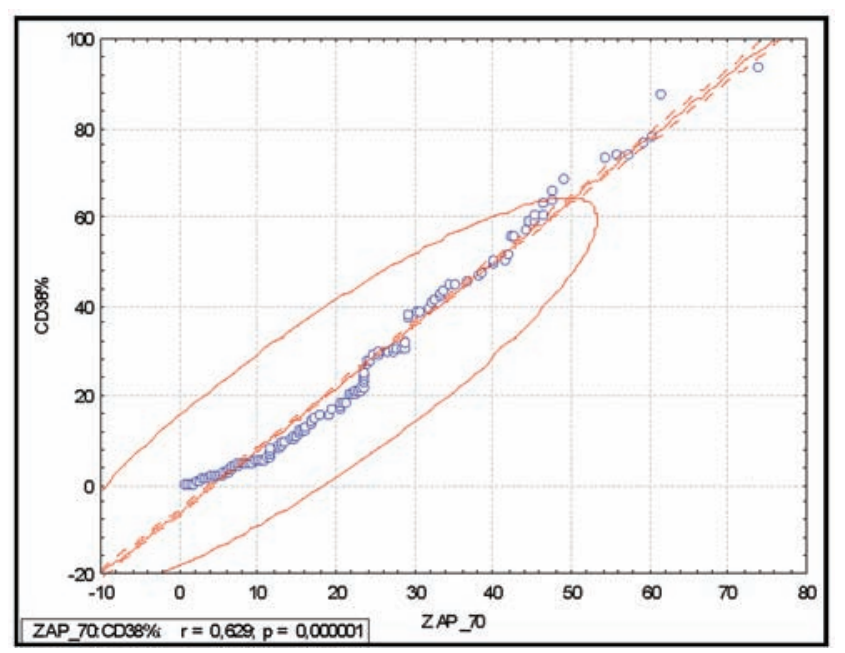

Fig. 1. Correlation between intracelullar expression of ZAP-70 and expression of CD38 on leukaemic cells (Spearman rank-correlation test).

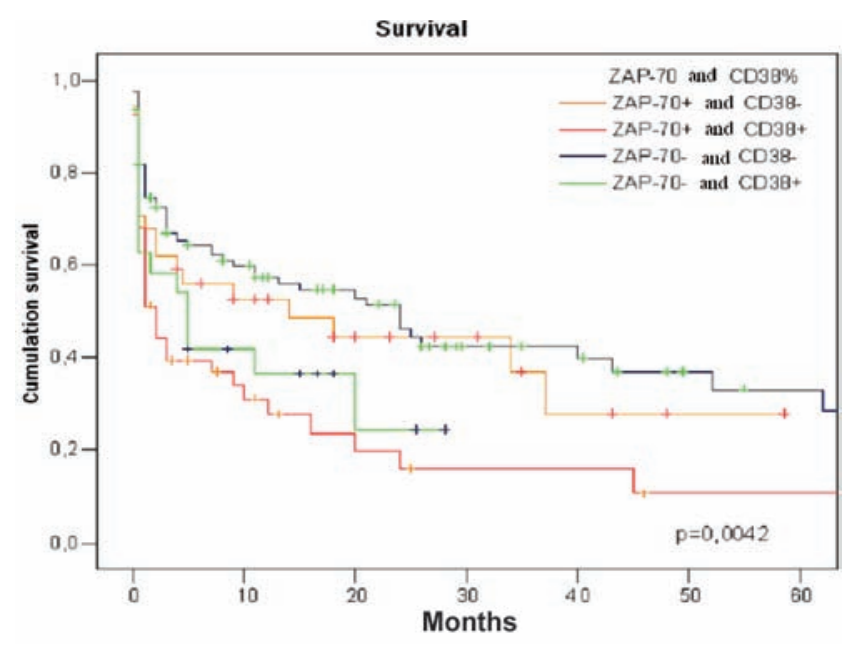

Fig. 2. Kaplan-Meier's curves presenting TFS in groups of B-CLL patients with phenotype: ZAP-70-CD38-; ZAP-70-CD38+; ZAP70+CD38-; ZAP-70+CD38+.

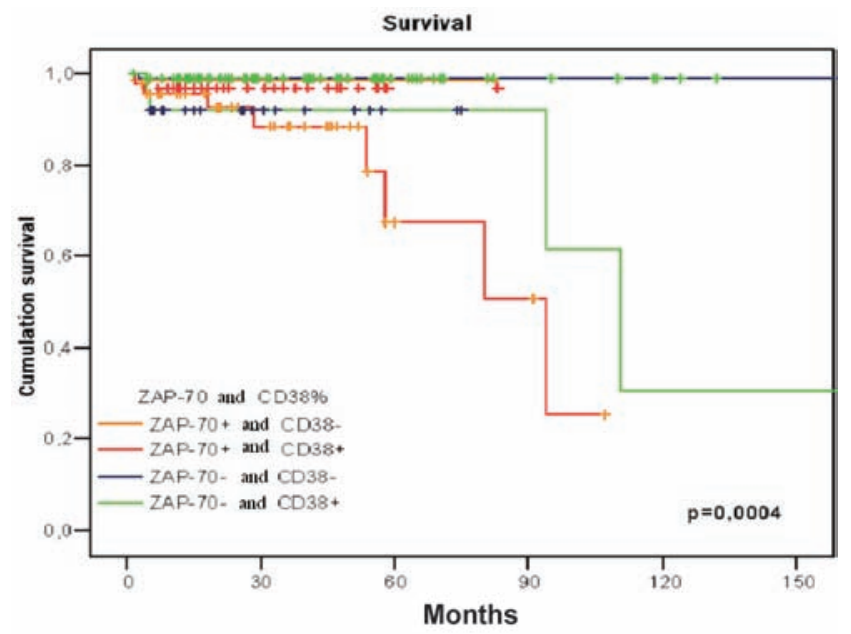

Fig. 3. Kaplan-Meier's curves presenting OS in groups of B-CLL patients with phenotype: ZAP-70-CD38-, ZAP-70-CD38+, ZAP70+CD38- and ZAP-70+CD38+. 
Table 3. Comparison of TFS in groups of patients with B-CLL with phenotype: ZAP-70-CD38-; ZAP-70-CD38+; ZAP-70+CD38-; ZAP$70+\mathrm{CD} 38+$

\begin{tabular}{|l|c|c|c|c|}
\hline & $\begin{array}{c}\text { ZAP-70- } \\
\text { CD38- }\end{array}$ & $\begin{array}{c}\text { ZAP-70- } \\
\text { CD38+ }\end{array}$ & $\begin{array}{c}\text { ZAP-70+ } \\
\text { CD38- }\end{array}$ & $\begin{array}{c}\text { ZAP-70+ } \\
\text { CD38+ }\end{array}$ \\
\hline No. of treated patients & 57 & 16 & 20 & 42 \\
\hline No.r of untreated patients & 48 & 9 & 14 & 11 \\
\hline TFS (mean; months) & 45.6 & 10.8 & 24.2 & 13.6 \\
\hline TFS (median; months) & 24 & 5 & 14 & 2 \\
\hline
\end{tabular}

Table 4. Comparison of OS in groups of patients with B-PBL with phenotype: ZAP-70-CD38-; ZAP-70-CD38+; ZAP-70+CD38-; ZAP$70+\mathrm{CD} 38+$.

\begin{tabular}{|l|c|c|c|c|}
\hline & ZAP-70-CD38- & ZAP-70-/CD38+ & ZAP-70+CD38- & ZAP-70+/CD38+ \\
\hline No. of patients who died & 2 & 4 & 3 & 10 \\
\hline No. of living patients & 103 & 21 & 31 & 43 \\
\hline OS (average, months) & 224,7 & 94,7 & 80,4 & 77,9 \\
\hline OS (median; months) & - & 94 & - & 94 \\
\hline
\end{tabular}

\section{Treatment-free survival (TFS) and overall survival (OS) in relation to combined ZAP-70 and CD38 expression}

In order to define the impact of simultaneous ZAP-70 and CD38 expression on TFS, the analysis of KaplanMeier's curves was done in the following groups of patients: ZAP-70+CD38+; ZAP-70-CD38-; ZAP-70CD38+ and ZAP-70+CD38-. It was found that TFS curves for groups ZAP-70-CD38- and ZAP$70+\mathrm{CD} 38+$, as well as groups ZAP-70+CD38- and ZAP-70+CD38+ showed essential differences $(\mathrm{p}=0.0004, \mathrm{p}=0.0499$, log-rank test). A significant difference in TFS between groups ZAP-70+CD38- and ZAP-70+CD38+ suggests that in the group of patients with positive ZAP-70 expression, defining CD38 expression enables also to distinguish patients with better and worse prognosis (Fig. 2). With the data presented in Table 3 one may come to conclusion that the longest TFS time is observed in patients with neither ZAP-70 nor CD38 expression.

The results of the TFS analysis show the best prognosis in patients with lack of ZAP-70 and CD38 expression, the group with the worst prognosis is the one with ZAP-70+CD38+ phenotype. It seems that the presence of positive CD38 expression on leukaemic cells is the most important parameter determining the shortening of TFS time.

The log-rank test showed significant difference in the OS curves for groups ZAP-70-CD38- and ZAP$70+\mathrm{CD} 38+$, as well as for ZAP-70-CD38- and ZAP$70-\mathrm{CD} 38+(\mathrm{p}=0.0001, \mathrm{p}=0.0023)$. A significant difference in OS between groups ZAP-70-CD38- and ZAP$70-\mathrm{CD} 38+$ suggests that additional defining of CD38 expression enables to distinguish patients with better and worse prognosis in ZAP-70- group (Fig. 3). Analysis of the data from Table 4 revealed that overall survival time was longer in ZAP-70-CD38- group in comparison with another three groups.

Additional information can be obtained by evaluating the survival curves in ZAP-70+CD38+ and ZAP70-CD38- groups depending on LDH activity, concentration of $\beta_{2} \mathrm{M}$ and hemoglobin. Because of lack of decrease in favorable prognosis groups, only TFS but not OS was defined. As for groups: $\mathrm{ZAP}+\mathrm{CD} 38+/ \mathrm{LDH}$ $>350 \mathrm{U} / \mathrm{l} ; \mathrm{ZAP}+\mathrm{CD} 38+/ \beta_{2} \mathrm{M}>3.0 \mathrm{mg} / \mathrm{L}$ and $\mathrm{ZAP}+$ $\mathrm{CD} 38+/ \mathrm{Hb}<12 \mathrm{~g} / \mathrm{dL}$ the mean TFS was: 51.76 ; 48.9 ; and 58.13 months and it was shorter in comparison with $\mathrm{ZAP}+\mathrm{CD} 38+$ patients (77.9 months).

\section{Discussion}

The aim of the presented study was to establish whether combined analysis of ZAP-70 and CD38 expression could improve predictive impact of both parameters. First, we confirmed their value as independent prognostic factors using multivariate Cox regression analysis. The importance of ZAP-70 as an independent prognosis parameter has been shown in numerous earlier studies $[10,15,16]$, in the case of CD38, this issue has been the matter of many controversies. Hamblin et al. in a multifactoral analysis, conducted in 2002, underlined that both $\operatorname{IgV}_{\mathrm{H}}$ mutational status and CD38 expression were independent prognostic factors [17], but according to Oscier et al. [18] the expression of CD38 cannot play the role of an independent prognostic parameter, but gives an additional predictive information in patients with defined $\operatorname{IgV}_{\mathrm{H}}$ mutational status. Other research concerning the 
value of $\mathrm{CD} 38$ as an independent prognosis parameter, also revealed divergent results $[8,15,16,19-22]$. The majority of recent studies conducted on large groups of patients confirms the predictive significance of CD38 expression.

For the clinical practice it is important to establish whether combined evaluation of the two independent prognostic factors, ZAP-70 and CD38 contribute to the increase in their predictive value. According to Orchard et al. CD38 expression has no influence on the increase in the prognostic significance of ZAP-70 and $\mathrm{IgV}_{\mathrm{H}}$ mutational status [15]. Similar conclusions were drawn by Del Principe et al. They stated that it was adequate just to evaluate ZAP-70 expression [16]. However, the results of our studies are in favor of simultaneous evaluation of both parameters that was presented in the earlier publication concerning the discussed issue [12]. The analysis showed the concordance in the results regarding the expression of the two studied antigens in $72.7 \%$ of patients. In the group with divergent results, $15.6 \%$ of patients were ZAP$70+\mathrm{CD} 38$ - and $11.5 \%$ were characterized by the phenotype of ZAP-70-CD38+. In the studies of Del Principe et al. the vast majority of patients from the group with divergent expression of both factors was characterized by the phenotype of ZAP-70+CD38$(82 \%)$ which, according to the authors indicated a major importance of ZAP-70 expression [16]. The results of our studies do not confirm such observations as the percentage of ZAP-70+CD38- and ZAP-70CD38+ patients was approximately the same. The most significant differences in laboratory parameters were found between ZAP-70-CD38- and ZAP$70+\mathrm{CD} 38+$ groups, whilst the differences between the two groups with divergent expression of studied antigens were not statistically significant. Corresponding observations deal with the evaluation of survival curves as well. Simultaneous evaluation of both antigen expression enables to distinguish subgroups with the best and the worst prognosis, which was revealed in the earlier studies of other authors [10,11]. Schroers et al, on the basis of combined evaluation of ZAP-70 and CD38 expression displayed three groups of patients: the good prognosis group (event-free survival, EFS 130 months; phenotype ZAP-70-CD38-); the poor prognosis group (EFS 30 months; phenotype ZAP-70+CD38+) and the intermediate prognosis group (EFS 43 months; phenotype ZAP-70+CD38+ and ZAP-70-CD38-) [10]. Similar data on the treatment free survival were presented by Del Giaudice et al, who also distinguished three groups with different prognosis on the basis of ZAP-70 and CD38 evaluation [11]. Furthermore, combined analysis used in our study enabled to separate subgroups in ZAP-70+ as well as in ZAP-70- patients, differing sometimes in OS and TFS time. Analogically, evaluation of ZAP-70 expression helps to distinguish additional subgroups among patients with positive or negative CD38 expression. These interdependences were acknowledged as significant for the prognosis by Durig et al. [4] and Bosch et al. [23]. The fact that the analysis of survival curves presented in our studies revealed that shortening of TFS depends more on CD38 expression, but ZAP-70 expression has a major impact on shortening of OS is in favor of the importance of combined evaluation of ZAP-70 and CD38 expression. Simultaneous evaluation of ZAP-70 and CD38 expression approves to enroll patients into an appropriate prognostic group in the case of threshold values of one of the evaluated parameters. The results of our study revealed also that analysis of ZAP-70 and CD38 expression together with chosen laboratory parameters with prognostic importance (concentration of hemoglobin and $\beta_{2} \mathrm{M}$, serum activity of LDH), enabled to distinguish patients with a shorter TFS time than in $\mathrm{ZAP}+\mathrm{CD} 38+$ group. These observations may be of great clinical value, since qualification of patients in early stages of B-CLL for the therapy on the basis of the presence of unfavourable prognostic parameters is more often considered. Our results suggest that standardized evaluation of ZAP-70 and CD38 expression ought to be included in the panel of routine laboratory tests studies at B-CLL diagnosis. However, whilst taking therapeutic decisions, it would be advisable to elaborate point system which would include both ZAP-70 and CD38 expression, as well as other laboratory parameters with determined prognostic value.

\section{References}

[ 1] Damle RN, Wasil T, Fais F, Ghiotto F, Valetto A, Allen SL, Buchbinder A, Budman D, Dittmar K, Kolitz J, Lichtman SM, Schulman P, Vinciguerra VP, Rai KR, Ferrarini M, Chiorazzi $\mathrm{N}$. Ig V gene mutation status and CD 38 expression as a novel prognostic indicators in chronic lymphocytic leukemia. Blood. 1999;94:1840-1847.

[ 2] Hamblin TJ, Davis Z, Gardiner A, Oscier DG, Stevenson FK. Unmutated Ig VH genes are associated with a more aggressive form of chronic lymphocytic leukemia. Blood. 1999;94: 1848-1854.

[3] Crespo M, Bosch F, Villamor N, Bellosillo B, Colomer D, Rozman M, Marcé S, López-Guillermo A, Campo E, Montserrat E. ZAP-70 expression as a surrogate for immunoglobulin-variable-region mutations in chronic lymphocytic leukaemia. $N$ Engl J Med. 2003;348:1764-75.

[ 4] Dürig J, Nückel H, Cremer M, Führer A, Halfmeyer K, Fandrey J, Möröy T, Klein-Hitpass L, Dührsen U. ZAP-70 expression is a prognostic factor in chronic lymphocytic leukaemia. Leukemia. 2003;17:2426-34.

[5] Ibrahim S, Keating M, Do KA, O'Brien S, Huh YO, Jilani I, Lerner S, Kantarjian HM, Albitar M. CD38 expression as an important prognostic factor in B-cell chronic lymphocytic leukemia. Blood. 2001;98:181-186.

[6] Heintel D, Schwarzinger I, Chizzali-Bonfadin C, Thalhammer R, Schwarzmeier J, Fritzer-Szekeres M, Weltermann A, Simonitsch I, Lechner K, Jaeger U. Association of CD38 antigen expression with other prognostic parameters in early 
stages of chronic lymphocytic leukemia. Leuk Lymphoma. 2001;42:1315-1321.

[ 7] Mainou-Fowler T, Dignum H, Taylor PR, Dickinson AM, Saunders PW, Proctor SJ, Summerfield GP. Quantification improves the prognostic value of CD38 expression in B-cell chronic lymphocytic leukaemia. Br J Haematol. 2002;118: 755-761.

[ 8] Domingo-Domenech E, Domingo-Clarós A, Gonzalez-Barca E, Beneitez D, Alonso E, Romagosa V, De Sanjos S, Petit J, Granena A, Fernández de Sevilla A. CD38 expression in Bchronic lymphocytic leukemia: association with clinical presentation and outcome in 155 patients. Haematologica. 2002; 87:1021-7.

[9] Gentile M, Mauro FR, Calabrese E, De Propris MS, Giammartini E, Mancini F, Milani ML, Guarini A, Foa R. The prognostic value of CD38 expression in chronic lymphocytic leukaemia patients studied prospectively at diagnosis: a single institute experience. Br J Haematol. 2005;130:549-57.

[10] Schroers R, Griesinger F, Trümper L, Haase D, Kulle B, Klein-Hitpass L, Sellmann L, Dührsen U, Dürig J. Combined analysis of ZAP-70 and CD38 expression as a predictor of disease progression in B-cell chronic lymphocytic leukemia. Leukemia. 2005;19:750-758.

[11] Del Giudice I, Morilla A, Osuji N, Matutes E, Morilla R, Burford A, Maravelaki S, Owusu-Ankomah K, Swansbury J, A'Hern R, Brito-Babapulle V, Catovsky D. Zeta-chain associated protein 70 and $\mathrm{CD} 38$ combined predict the time to first treatment in patients with chronic lymphocytic leukemia. Cancer. 2005;15:2124-32.

[12] Hus I, Podhorecka M, Bojarska-Junak A, Roliński J, Schmitt M, Sieklucka M, Wasik-Szczepanek E, Dmoszyńska A. The clinical significance of ZAP-70 and CD38 expression in Bcell chronic lymphocytic leukaemia. Ann Oncol. 2006;17: 683-90.

[13] Cheson BD, Bennett JM, Grever M, Kay N, Keating MJ, O'Brien S, Rai KR. National Cancer Institute-sponsored Working Group guidelines for chronic lymphocytic leukemia: revised guidelines for diagnosis and treatment. Blood. 1996; 87:4990-4997.

[14] Bojarska-Junak A, Giannopoulos K, Kowal M, Dmoszyńska A, Roliński J. Comparison of Methods for Determining ZetaChain Associated Protein - 70 (ZAP-70) Expression in Patients with B-Cell Chronic Lymphocytic Leukemia (BCLL). Cytometry B Clin Cytom. 2006;70B:293-301.

[15] Orchard JA, Ibbotson RE, Davis Z, Wiestner A, Rosenwald A, Thomas PW, Hamblin TJ, Staudt LM, Oscier DG. ZAP-70 expression and prognosis in chronic lymphocytic leukaemia. Lancet. 2004;363:105-11.
[16] Del Principe MI, Del Poeta G, Buccisano F, Maurillo L, Venditti A, Zucchetto A, Marini R, Niscola P, Consalvo MA, Mazzone C, Ottaviani L, Panetta P, Bruno A, Bomben R, Suppo G, Degan M, Gattei V, de Fabritiis P, Cantonetti M, Lo Coco F, Del Principe D, Amadori S. Clinical significance of ZAP-70 protein expression in B-cell chronic lymphocytic leukemia. Blood. 2006;108:853-861.

[17] Hamblin TJ, Orchard JA, Ibbotson RE, Davis Z, Thomas PW, Stevenson F. CD38 expression and immunoglobulin variable region mutations are independent prognostic variables in chronic lymphocytic leukemia, but CD38 expression may vary during the course of the disease. Blood. 2002;99:10231029.

[18] Oscier DG, Gardiner AC, Mould SJ, Glide S, Davis ZA, Ibbotson RE, Corcoran MM, Chapman RM, Thomas PW, Copplestone JA, Orchard JA, Hamblin TJ. Multivariate analysis of prognostic factors in CLL: clinical stage, IGV $_{\mathrm{H}}$ gene mutational status, and loss or mutation of $\mathrm{p} 53$ gene are independent prognostic factors. Blood. 2002;100:1177-1184.

[19] Matrai Z, Lin K, Dennis M, Sherrington P, Zuzel M, Pettitt AR, Cawley JC. CD38 expression and Ig VH gene mutation in B-cell chronic lymphocytic leukemia. Blood. 2001;97: 1902-1903.

[20] Jelinek DF, Tschumper RC, Geyer SM, Bone ND, Dewald GW, Hanson CA, Stenson MJ, Witzig TE, Tefferi A, Kay NE. Analysis of clonal B-cell CD38 and immunoglobulin variable region sequence status in relation to clinical outcome for Bchronic lymphocytic leukaemia. Br J Haematol. 2001;115: 854-861.

[21] Thunberg U, Johnson A, Roos G, Thörn I, Tobin G, Sällström J, Sundström C, Rosenquist R. CD38 expression is a poor predictor for $\mathrm{VH}$ gene mutational status and prognosis in chronic lymphocytic leukemia. Blood. 2001;97:1892-1894.

[22] Kröber A, Seiler T, Benner A, Bullinger L, Brückle E, Lichter P, Döhner H, Stilgenbauer S. VH mutation status, CD38 expression level, genomic aberrations, and survival in chronic lymphocytic leukemia. Blood. 2002;100:1410-1416.

[23] Bosch F, Crespo M, Villamor N, Muntanola A, Ferrer A, Domingo A: Clinical characteristics and outcome of a large series of patients with CLL according to ZAP-70 expression. Blood. 2004;104:8a. 